\title{
Patogenicidade e virulência de Toxoplasma gondii isolado de suínos de criação artesanal no sul do Brasil ${ }^{1}$
}

\author{
Plínio Aguiar de Oliveira ${ }^{2 *}$, Fernando Caetano de Oliveira² ${ }^{2}$ Laura Maria Jorge de \\ Faria $^{2}$, Beatris Gonzalez Cademartori ${ }^{2}$, Clairton Marcolongo-Pereira ${ }^{3}$, Ana Carolina \\ Barreto Coelho ${ }^{3}$, Felipe Geraldo Pappen ${ }^{4}$ e Nara Amélia Farias ${ }^{2}$

\begin{abstract}
Oliveira P.A., OliveiraF.C., Faria L.M.J., Marcolongo-Pereira C., Coelho A.C.B., Pappen F.G. \& Farias N.A.R. 2014. [Patogenicity and virulence of Toxoplasmagondii isolated from rustic farm pigs in Southern Brazil.] Patogenicidade e virulência de Toxoplasma gondii isolado de suínos de criação artesanal no sul do Brasil. Pesquisa Veterinária Brasileira 34(12):1186-1190. Departamento de Parasitologia e Microbiologia, Instituto de Biologia, Universidade Federal de Pelotas, Campus Universitário s/n, Pelotas, RS 96010900, Brazil. E-mail: plinio-vet@hotmail.com

Studies of Toxoplasma gondii infection in pigs are important because they are part of the human food chain. The main routes of transmission of this agent are: carnivorism, fecal-oral and congenital. Six isolates of T. gondii from pigs of rustic farms were evaluated for virulence and pathogenicity. Tachyzoites suspension used in the tests was obtained by aspiration or by washing the peritoneal cavity of mice that had developed ascites. Each sample of living tachyzoites was inoculated into groups of five mice with inoculum of $10^{1}, 10^{2}, 10^{3}$, $10^{4}, 10^{5}$ and $10^{6}$ intraperitoneally. Half of the isolates $(3 / 6)$ were lethal and caused clinical signs in Swiss albino mice. The minimum lethal dose was $10^{3}$ tachyzoites by inoculum. The death of mice that had acute infection occurred between 12 and 26 days post-inoculation. The other three isolates were not pathogenic or virulent for mice. All isolates of the area studied had a high ability to form cysts, what could increase the risk for infection through ingestion of infected animal tissues.
\end{abstract}

INDEX TERMS: Toxoplasma gondii, isolates, swine, artisanal handling.

RESUMO.- Estudos com Toxoplasma gondii em suínos são relevantes porque seus produtos e subprodutos fazem parte da cadeia alimentar do ser humano. As principais vias de transmissão deste agente são o carnivorismo, fecal-oral e congênita. Seis isolados de Toxoplasma gondii de suínos de criação artesanal foram avaliados quanto à patogenicidade e virulência em camundongos suíços albinos. A suspensão de taquizoítos utilizada nos testes foi obtida através da punção ou lavagem da cavidade peritoneal de camundongos que apresentaram ascite. Cada amostra foi inoculada

\footnotetext{
${ }^{1}$ Recebido em 30 de abril de 2014.

Aceito para publicação em 13 de novembro de 2014

${ }^{2}$ Laboratório de Parasitologia, Departamento de Microbiologia e Parasitologia, Universidade Federal de Pelotas (UFPel), Campus Universitário, Capão do Leão s/n, Pelotas, RS 96010-900, Brasil. *Autor para correspondência: plinio-vet@hotmail.com

${ }^{3}$ Laboratório Regional de Diagnóstico, Faculdade de Veterinária, UFPel, Pelotas, RS.

${ }^{4}$ Instituto Federal Tecnológico, Campus Concórdia, Rodovia SC-283 Km 8, Cx. Postal 58, Concórdia, SC 89700-000, Brasil.
}

em grupos de cinco camundongos, com inóculo de $10^{1}, 10^{2}$, $10^{3}, 10^{4}, 10^{5}$ e $10^{6}$ taquizoítos vivos, via intraperitoneal. Dos isolados, $50 \%$ (3/6) foram letais e causaram sinais clínicos nos camundongos. A dose mínima letal foi de $10^{3}$ taquizoítos. A morte dos animais que apresentaram infecção aguda ocorreu entre 12 e 26 dias após a inoculação. Todos os isolados da região estudada apresentam alta capacidade de formar cistos, o que pode aumentar o risco de infecção pela ingestão de tecidos dos animais infectados pelos mesmos.

TERMOS DE INDEXAÇÃO: Toxoplasma gondii, isolado, suínos, criação artesanal.

\section{INTRODUÇÃO}

Toxoplasma gondii, protozoário cosmopolita, intracelular obrigatório, é agente de uma das infecções parasitárias mais comuns do homem, dos animais domésticos e selvagens (Dubey 2010). As principais formas de infecção ocorrem por via oral, através da ingestão de carne mal cozida contendo cistos, de alimentos e água contaminados com 
oocistos eliminados nas fezes de gatos infectados, ou ainda pela via transplacentária (Dubey \& Jones 2008).

Os suínos são hospedeiros intermediários com grande importância para a manutenção de T. gondii na natureza, seus produtos e subprodutos são uma importante fonte de infecção para o homem (Jongert et al. 2008). A maioria dos suínos se infecta com o protozoário após o nascimento, por ingestão de oocistos no ambiente contaminado ou ingestão de tecidos de animais infectados (Kijlstra et al. 2008). Nas criações artesanais, a possível ingestão de roedores, pássaros, vísceras de animais de abate doméstico e alimentos ou água contaminados, aumenta o risco de infecção (Dubey 2009).

O isolamento do parasito por bioensaio em camundongos utilizando tecidos de suínos tem sido realizado a partir de vários tecidos, como cérebro, coração, língua e diafragma (Garcia et al. 2006, Velmurugan et al. 2009, Bezerra et al. 2012). Genótipos Tipo I, Tipo III e atípicos de T. gondii já foram identificados nesses hospedeiros (Santos et al. 2005, Garcia et al. 2006, Belfort-Neto et al. 2007, Velmurugan et al. 2009, Bezerra et al. 2012).

Estudos realizados em diferentes regiões e hospedeiros confirmaram que os isolados de T. gondii do Brasil são biológica e geneticamente diferentes daqueles da América do Norte e Europa, apresentando uma alta diversidade genética (Pena et al. 2008, Andrade et al. 2013).

Amostras de T. gondii têm sido diferenciadas através da patogenicidade, entendida pela capacidade do agente, uma vez instalado, de produzir sinais clínicos e pela virulência, sendo esta a capacidade do agente de produzir efeitos graves ou fatais (Pereira 2004). A patogenicidade varia com o hospedeiro, estágio do parasito, via de inoculação e dose infectante. Assim, para conhecer realmente a patogenicidade devem ser ministradas quantidades conhecidas do agente (Dubey 1978, Willians et al. 1978).

Cepas de T. gondii são tidas como virulentas quando a inoculação via intraperitoneal de menos de 100 taquizoítos provocam sinais clínicos agudos em camundongos, levando-os à morte em aproximadamente uma semana; avirulentas, quando a inoculação de doses maiores, como $10^{3}$ ou $10^{4}$ taquizoítos, não causa sinais clínicos significativos e formação de cistos no cérebro (Johnson 1997). A virulência, quando determinada pelo isolamento, sem o conhecimento da dose infectante pode levar a resultados imprecisos (Andrade et al. 2013).

0 objetivo deste estudo foi avaliar a patogenicidade e virulência de amostras de $T$. gondii procedentesde suínos de criação artesanal, naturalmente infectados, do sul do Rio Grande do Sul.

\section{MATERIAL E MÉTODOS}

Foram analisadas amostras de sangue e tecidos (encéfalo e coração) de 12 suínos criados artesanalmente e abatidos para consumo humano. Quatro isolados $(97,98,99,100)$ utilizados foram descritos por Cademartori et al. (2014) e as demais oito amostras foram coletadas em seis municípios do Rio Grande do Sul (Capão do Leão, Cerrito, Morro Redondo, Piratini, Pelotas e São Lourenço do Sul), situados entre os paralelos $31^{\circ} 21^{\prime \prime}$ e $31^{\circ} 46^{\prime \prime} \mathrm{S}$ e os meridianos $53^{\circ} 06^{\prime \prime}$ e $51^{\circ} 58^{\prime \prime} \mathrm{W}$.
As amostras foram obtidas e identificadas no momento do abate dos animais nas propriedades, acondicionadas e transportadas em caixas térmicas até o Laboratório de Parasitologia da Universidade Federal de Pelotas (UFPel).

Os soros provenientes das amostras de sangue foram examinados para detecção de anticorpos IgG para Toxoplasma gondii através da Reação de Imunofluorescência Indireta (RIFI), conforme técnica descrita por Camargo (1974), utilizando antígeno comercial (Wama Diagnostica, São Carlos, SP) (cepa ME49) e o conjugado IgG anti-suíno (Sigma Chemical ${ }^{\circledR}$ Co., St Louis, MO, USA). Foi utilizado o ponto de corte de 1:64 (Millar 2008). Em todas as reações, foram incluídos soros controle positivo e negativo, previamente conhecidos.

Para o isolamento, obtenção de taquizoítos e avaliação da patogenicidade e virulência das amostras de T. gondii, foram utilizados camundongos suíços albinos (Mus musculus), fêmeas, com aproximadamente dois meses de idade, provenientes do Biotério Central da Faculdade de Medicina Veterinária, UFPel.

No bioensaio em camundongos, encéfalo e coração de suínos que apresentaram sorologia positiva para T. gondii, foram triturados, homogeneizados e preparados por digestão péptica, conforme descrito por Dubey (1998). Fragmentos de $25 \mathrm{~g}$ de encéfalo e $25 \mathrm{~g}$ de coraçãode cada suíno foram triturados e homogeneizados com 125 volt (v/v) de solução salinaestéril e5vol de pepsina ácida.A mistura foi incubada em banho-maria a $37^{\circ} \mathrm{C}$, por uma hora. $\mathrm{O}$ homogeneizado foi filtrado através de duas camadas de gaze e centrifugado a $1200 \mathrm{~g}$ por 10 minutos. Após a centrifugação, o sobrenadante foi descartado e adicionou-se ao sedimento solução neutralizadora (1,2\% bicarbonato de sódio, $\mathrm{pH}$ 8,3). 0 material foi centrifugado a $1200 \mathrm{~g}$, por 10 minutos, e o sobrenadante descartado. 0 sedimento foi ressuspendido com $5 \mathrm{ml}$ de solução, contendo 1000 UI penicilina e $100 \mu \mathrm{g}$ de estreptomicina por $1 \mathrm{ml}$ de solução salina estéril. Duas doses de $1 \mathrm{ml}$ do homogeneizado dos tecidos foram inoculados intraperitonealmente, em cinco camundongos para cada suíno analisado, com intervalo de 24 horas.

Os animais foram observados diariamente e, aqueles que sobreviveram à infecção, foram sacrificados 60 dias pós-inoculação (pi), para pesquisa de anticorpos e cistos teciduais. Porções de coração, pulmões e encéfalo desses camundongos, foram utilizadas para inocular novos animais experimentais (repassagem), buscando a obtenção de taquizoítos (fase aguda), em um máximo de quatro passagens. Todos os animais utilizados no bioensaio foram analisados quanto à presença de cistos teciduais através de avaliação histopatológica.

Foram realizadas avaliações de patogenicidade e virulência do parasito para camundongos, somente dos isolados que causaram infecção aguda nos animais experimentais. A suspensão de taquizoítos foi obtida através da punção e/ou lavagem da cavidade peritoneal dos camundongos. Os taquizoítos obtidos foram suspensos em solução salina estéril e padronizados por contagem em câmara de Neubauer. Cada amostra de $1 \mathrm{ml}$ foi inoculada em grupos de cinco camundongos, com inóculos de $10^{1}, 10^{2}, 10^{3}, 10^{4}$, $10^{5}$ e $10^{6}$ taquizoítos vivos, via intraperitoneal. 0 grupo controle recebeu apenas $1 \mathrm{ml}$ de solução salina estéril, e os camundongos foram observados diariamente.

Fragmentos de pulmão, cérebro, fígado e baço dos camundongos que morreram pela infecção, ou que foram eutanasiados, foram fixados em formalina $10 \%$, cortados com $5 \mu$ de espessura, corados com hematoxilina-eosina e observados microscopicamente para a pesquisa de taquizoítos ou cistos do parasito.

A pesquisa foi realizada com a aprovação da Comissão de Ética em Experimentação Animal da Universidade Federal de Pelotas (CEEA no 2300). 


\section{RESULTADOS}

Dos 12 suínos analisados, oito (67\%) foram soropositivos para Toxoplasma gondii. Estes eram provenientes dos municípios de Piratini, Cerrito, Capão do Leão e Pelotas. Das oito amostras soropositivas, o parasito foi isolado, por meio do bioensaio em camundongos, em seis delas (75\%). Desses seis isolados, um $(16,7 \%)$ foi obtido durante a passagem suíno/camundongo (suíno 97) e os demais após passagens camundongo/camundongo: um isolado $(16,7 \%)$ na primeira passagem (suíno 98), outro na segunda passagem (suíno 99) e os outros três (50\%) foram obtidos na quarta passagem (suínos 100, 101 e 102).

Em relação à patogenicidade dos isolados obtidos, em três deles(97, 98 e 100) foram observados sinais clínicos de toxoplasmose aguda (Quadro 1) enquanto nos outros três $(99,101$ e 102) foi observado a forma crônica da doença, diagnosticada pela presença de cistos do parasito nos tecidos.

Em relação à patogenicidade, realizada somente com os isolados que levaram a um quadro clínico da doença, observou-se que o isolado 100 foi capaz de causar sinais clínicos e morte dos animais experimentais com menor inoculo ( $10^{3}$ taquizoítos) e os isolados 97 e 98 provocaram a morte dos camundongos com inóculo 100 vezes maior ( $10^{5}$ taquizoítos). 0 tempo decorrido entre a inoculação e o surgimento dos sinais clínicos de todos os isolados variou de 9 a 18 dias e o período entre a inoculação e a morte dos camundongos variou de 12 a 26 dias (Quadro 2).

As alterações macroscópicas e histológicas observadas são apresentadas no Quadro 3. Foram observados cistos nos tecidos dos camundongos que receberam os inóculos dos isolados 97,98 e $100\left(10^{2}\right.$ a $\left.10^{6}\right)$ e que apresentaram quadro clínico, bem como naqueles que apresentaram a forma crônica da doença e nos quais os isolados não foram quantificados para avaliação de patogenicidade. Dos grupos estudados, foram encontradas estruturas morfologicamente compatíveis com cistos de T. gondii em 52,4\% (55/105), destes $54,5 \%(30 / 55)$ no pulmão e fígado, $27,3 \%(15 / 55)$ no pulmão e $18,2 \%(10 / 55)$ no fígado. Nenhum cisto foi observado no cérebro. As lesões histológicas encontradas foram características de hepatite multifocal e pneumonia necrosante, geralmente associadas à presença de cistos do parasito nesses órgãos (Quadro 3).

\section{DISCUSSÃO}

Os resultados obtidos no presente estudo podem ser um indicativo da condição sanitária e do risco de infecção por Toxoplasma gondii dos suínos das propriedades e da população na região estudada, uma vez que, mesmo com o número bastante baixo de suínos amostrados, foram encontrados animais soropositivos para T. gondii em dois terços dos municípios avaliados (Damriyasa et al. 2004).

A taxa de isolamento de $75 \%$ do parasito pelo bioensaio em camundongos feito com o tecido dos suínos soropositivos, foi superior à encontrada no Estado de São Paulo, de $25 \%$, também em suínos soropositivos (Santos et al. 2005). 0 uso de amostras de suínos de criação artesanal, coletadas no momento do abate, pode ter influenciado a taxa observada no presente estudo. Esta pode variar de acordo com detalhes de metodologia utilizados no bioensaio, como número de camundongos utilizados por tecido, forma de digestão dos tecidos e o procedimento de coleta das amostras (Dubey 2009).

No presente estudo três isolados $(97,98$ e 100) demonstraram ser virulentos, causando mortalidade nos camundongos do bioensaio, enquanto que os isolados 99, $101 \mathrm{e}$ 102 não revelaram essa característica. Além disso, o tempo decorrido desde a inoculação até a morte dos camundongos (12 a 26 dias) foi similar ao observado por Dubey et al. (2007) em isolados obtidos de galinhas desta mesma região (13 a 23 dias). A virulência de uma cepa é definida com base na mortalidade de camundongos infectados e o tempo entre a inoculação e a morte dos animais (Su et al. 2006). Nos três isolados que causaram a forma aguda da doença o tempo decorrido entre a inoculação e a morte, foi inversamente proporcional ao número de taquizoítos do inóculo.

A variação de patogenicidade e virulência dos isolados de T. gondii puderam ser confirmadas, no presente estudo, pelas diferenças de mortalidade dos camundongos que receberam diferentes e conhecidas quantidades de taquizoítos de cada um dos isolados. Além disso, $50 \%$ dos isolados causaram infecção aguda nos camundongos e os outros

Quadro 1. Frequência dos sinais clínicos de toxoplasmose observados em camundongos inoculados com tecidos de suínos naturalmente infectados ( $\mathrm{n}=30$ camundongos/suíno)

\begin{tabular}{|c|c|c|c|c|c|c|c|}
\hline \multirow{2}{*}{$\begin{array}{l}\text { Sinais clínicos } \\
\text { (\% de animais) }\end{array}$} & \multicolumn{4}{|c|}{ Identificação do suíno* } & & & \multirow[t]{2}{*}{ №/\% geral } \\
\hline & 97 & 98 & 99 & 100 & 101 & 102 & \\
\hline Ascite & $10 / 30(33,3)$ & $3 / 30(10)$ & - & $5 / 30(16,7)$ & - & - & $18 / 180(10)$ \\
\hline Pelos arrepiados & $15 / 30(50)$ & $15 / 30(50)$ & $20 / 30(66,7)$ & $20 / 30(66,7)$ & - & - & $70 / 180(38,9)$ \\
\hline Dispnéia & $5 / 30(16,7)$ & - & - & $15 / 30(50)$ & - & - & $20 / 180(11,1)$ \\
\hline Tremores & $10 / 30(33,3)$ & $10 / 30(33,3)$ & - & $5 / 30(16,7)$ & - & - & $25 / 180(13,9)$ \\
\hline Incoordenação & $5 / 30(16,7)$ & $15 / 30(50)$ & - & - & - & - & $20 / 180(11,1)$ \\
\hline Apatia & $10 / 30(33,3)$ & 33,3 & - & $20 / 30(66,7)$ & - & - & $40 / 180(22,2)$ \\
\hline Inanição & $5 / 30(16,7)$ & - & - & $20 / 30(66,7)$ & - & - & $25 / 180(13,9)$ \\
\hline Emagrecimento & $5 / 30(16,7)$ & 33,3 & - & $20 / 30(66,7)$ & - & - & $35 / 180(19,4)$ \\
\hline Desidratação & $10 / 30(33,3)$ & - & - & $10 / 30(33,3)$ & - & - & $20 / 180(11,1)$ \\
\hline Cianose & $15 / 30(50)$ & $15 / 30(50)$ & - & $20 / 30(66,7)$ & - & - & $50 / 180(27,8)$ \\
\hline Diarréia & - & $3 / 30(10)$ & - & $5 / 20(16,7)$ & - & - & $8 / 180(4,5)$ \\
\hline
\end{tabular}

* Pool de coração e encéfalo para cada suíno analisado. 
Quadro 2. Avaliação da patogenicidade de isolados de Toxoplasma gondii, obtidos de suínos, através da inoculação em camundongos ( $n=5$ camundongos por isolado) de diferentes concentrações de taquizoítos

\begin{tabular}{ccccc}
\hline Isolado & $\begin{array}{c}\text { Inóculo } \\
\text { (taqui- } \\
\text { zoítos) }\end{array}$ & $\begin{array}{c}\text { Início dos } \\
\text { sinais clínicos } \\
\text { (d.p.i) }\end{array}$ & $\begin{array}{c}\text { № de camundon- } \\
\text { gos com sinais } \\
\text { clínicos/mortos }\end{array}$ & $\begin{array}{c}\text { Morte (no. de } \\
\text { camundongos) } \\
\text { d.p.i }\end{array}$ \\
\hline 97 & $10^{6}$ & 10 & $5 / 5$ & $13(1), 14(2), 15(2)$ \\
97 & $10^{5}$ & 13 & $5 / 5$ & $16(5)$ \\
97 & $10^{4}$ & 17 & $5 / 0$ & - \\
97 & $10^{3}$ & SSN & - & - \\
97 & $10^{2}$ & SSN & - & - \\
97 & $10^{1}$ & SSN & - & - \\
98 & $10^{6}$ & 14 & $3 / 3$ & $18(1), 21(2)$ \\
98 & $10^{5}$ & 18 & $2 / 2$ & $23(1), 25(1)$ \\
98 & $10^{4}$ & SSN & - & - \\
98 & $10^{3}$ & SSN & - & - \\
98 & $10^{2}$ & SSN & - & - \\
98 & $10^{1}$ & SSN & - & $12(1), 13(4)$ \\
100 & $10^{6}$ & 9 & $5 / 5$ & $12(1), 13(1), 16(3)$ \\
100 & $10^{5}$ & 11 & $5 / 5$ & $21(5)$ \\
100 & $10^{4}$ & 16 & $5 / 5$ & - \\
100 & $10^{3}$ & 18 & $5 / 5$ & $22(4), 26(1)$ \\
100 & 102 & SSN & - & - \\
100 & $10^{1}$ & SSN & - & \\
\hline d.p.i. = dias pós-inoculação.SSN = sem sinais clínicos. & \\
\multicolumn{5}{c}{}
\end{tabular}

Quadro3. Alterações histológicas e presença de cistos nos órgãos dos camundongos do bioensaio e que receberam diferentes inóculosde taquizoítos deToxoplasma gondii isolados de suínos $(\mathbf{n = 5})$

\begin{tabular}{lcccc}
\hline Isolado & $\begin{array}{c}\text { Inóculo } \\
\text { (taquizoítos) }\end{array}$ & Cisto & \multicolumn{2}{c}{ Alterações patológicas } \\
\cline { 4 - 5 } & & Macroscópicas & Microscópicas \\
\hline 97 & $10^{6}$ & $\mathrm{P}$ & $\mathrm{S} / \mathrm{A}$ & Pneumonia e hepatite \\
97 & $10^{5}$ & $\mathrm{P}$ & $\mathrm{S} / \mathrm{A}$ & Pneumonia \\
97 & $10^{4}$ & $\mathrm{~N}$ & $\mathrm{~S} / \mathrm{A}$ & Pneumonia \\
97 & $10^{3}$ & $\mathrm{~N}$ & $\mathrm{~S} / \mathrm{A}$ & $\mathrm{S} / \mathrm{A}$ \\
97 & $10^{2}$ & $\mathrm{~N}$ & $\mathrm{~S} / \mathrm{A}$ & $\mathrm{S} / \mathrm{A}$ \\
97 & $10^{1}$ & $\mathrm{~N}$ & $\mathrm{~S} / \mathrm{A}$ & $\mathrm{S} / \mathrm{A}$ \\
98 & $10^{6}$ & $\mathrm{P}$ & $\mathrm{S} / \mathrm{A}$ & Pneumonia \\
98 & $10^{5}$ & $\mathrm{P}$ & $\mathrm{S} / \mathrm{A}$ & Pneumonia \\
98 & $10^{4}$ & $\mathrm{~N}$ & $\mathrm{~S} / \mathrm{A}$ & $\mathrm{S} / \mathrm{A}$ \\
98 & $10^{3}$ & $\mathrm{~N}$ & $\mathrm{~S} / \mathrm{A}$ & $\mathrm{S} / \mathrm{A}$ \\
98 & $10^{2}$ & $\mathrm{~N}$ & $\mathrm{~S} / \mathrm{A}$ & $\mathrm{S} / \mathrm{A}$ \\
98 & $10^{1}$ & $\mathrm{~N}$ & $\mathrm{~S} / \mathrm{A}$ & $\mathrm{S} / \mathrm{A}$ \\
100 & $10^{6}$ & $\mathrm{P}$ & Hepatomegalia, & Pneumonia e hepatite \\
& & & esplenomegalia & \\
100 & $10^{5}$ & $\mathrm{P}$ & Hepatomegalia, & Pneumonia e hepatite \\
& & & esplenomegalia & \\
100 & $10^{4}$ & $\mathrm{P}$ & S/A & Pneumonia e hepatite \\
100 & $10^{3}$ & $\mathrm{P}$ & S/A & Pneumonia e hepatite \\
100 & $10^{2}$ & $\mathrm{~N}$ & S/A & Hepatite \\
100 & $10^{1}$ & $\mathrm{~N}$ & S/A & S/A \\
$99^{*}$ & & $\mathrm{P}$ & S/A & Pneumonia e hepatite \\
$101^{*}$ & & $\mathrm{P}$ & S/A & Hepatite \\
$102^{*}$ & & $\mathrm{P}$ & S/A & Hepatite \\
\hline & & $\mathrm{N}$ &
\end{tabular}

$\mathrm{P}=$ presença de cisto, $\mathrm{N}=$ ausência de cisto, $\mathrm{S} / \mathrm{A}=$ sem alterações, ${ }^{*}$ Animais do bioensaio.

50\% causaram infecção crônica, sem alterações clínicas ou morte dos animais. Resultados similares foram observados por Dubey et al. (2007) ao avaliarem isolados de galinhas caipiras desta mesma região (44\% causaram infecção aguda e morte dos camundongos inoculados). As diferenças de patogenicidade e virulência são mais evidentes nos casos em que há morte dos camundongos, como o observado no estágio agudo da doença, ou nos casos em que os camundongos infectados sobrevivem por mais tempo, como o observado na forma crônica da doença (Dubremetz \& Lebrun 2012). É importante ressaltar o inóculo mínimo de $10^{3}$ taquizoítos que foi capaz de matar os camundongos. Em um estudo que avaliou três isolados de suínos das cidades de Londrina (PR) e Erechim (RS), foi necessária uma concentração de taquizoítos dez vezes maior que a encontrada no presente trabalho para observação de mortalidade em camundongos (Mitsuka et al. 1998). Isto pode ser explicado pela maior patogenicidade e virulência dos isolados do presente estudo.

$\mathrm{O}$ fato de terem sido observadas estruturas morfologicamente compatíveis com cistos de T. gondii nas amostras de pulmão e fígado dos animais com infecção aguda e crônica, tanto nos animais do bioensaio quanto nos diferentes inóculos, sugere que estes isolados não apresentaram a característica neurotrópica comum a este parasito (Dubey et al. 2004). T. gondii foi também observado em ovários e músculos das pernas de galinhas nos Estados Unidos com infecção crônica, mas nenhum parasito foi encontrado no sistema nervoso central destas aves (Jabos \& Melton 1966).

Além disso, Dubey et al. (2005) não observaram estruturas compatíveis com cistos de T. gondii nos camundongos sobreviventes, após 50 dias da inoculação. Isto demonstra diferenças entre a capacidade cistogênica dos isolados, pois todos os isolados aqui descritos foram capazes de induzir à formação de cistos nos animais inoculados. A capacidade cistogênica dos isolados encontrados neste estudo sugere a presença de T. gondii nos tecidos de suínos da região. Alerta-se para o alto risco de infecção humana, principalmente para pessoas que consomem produtos e subprodutos de suínos de criatórios artesanais.

Agradecimentos.- À equipe do Biotério Central (UFPel), do Laboratório Regional de Diagnóstico (UFPel) e do Laboratório de Parasitologia do Instituto de Biologia (UFPel), pelo empenho em todas as etapas desse estudo.

\section{REFERÊNCIAS}

Belfort-Neto R., Nussenblatt V., Rizzo L., Muccioli C., Silveira C., Nussenblatt R., Khan A., Sibley L.D. \& Belfort-Jr R. 2007. High prevalence of unusualgenotypes of Toxoplasmagondiiinfection in porkmeatsamplesfrom Erechim, Southern Brazil. Anais Acad. Bras. Cienc. 79(1):111-114.

Bezerra R.A., Carvalho F.S., Guimarães L.A., Rocha D.S., Maciel B.M., Wenceslau A.A., Lopes C.W.G. \& Albuquerque G.R. 2012. Genetic characterization of Toxoplasma gondii isolation from pigs intended for human consumption in Brazil. Vet. Parasitol. 189:153-161.

Bezerra R.A., Paranhos E.B., Del'Arco A.E. \& Albuquerque G.R. 2009. Detecção de anticorpos anti-Toxoplasmagondii em suínos criados e abatidos no Estado da Bahia, Brasil. Revta Bras. Parasitol. Vet. 18(3):78-80.

Camargo M.E. 1974. Introdução às técnicas de imunofluorescência. Revta Bras. Patol. Clín. 10:143-169.

Cavalcante G.T., Aguiar D.M., ChiebaoD., Dubey J.P., Ruiz V.L.A., Dias R.A., Camargo L.M.A., Labruna M.B. \& Gennari S.M. 2006. Seroprevalence of Toxoplasma gondii antibodies in cats and pigs from rural western Amazon, Brazil. J. Parasitol. 92(4):863-864.

Damriyasa I.M., Bauera C., Edelhoferb R., Failing K., Lind P., Petersene E., Schares G., Tenterg A.M., Volmerh R. \& Zahnera H. 2004. Cross-sectional survey in pig breeding farms in Hessen, Germany: seroprevalence and risk factors of infections with Toxoplasma gondii, Sarcocystis spp. and Neospora caninum sows. Vet. Parasitol. 126:271-286. 
De Azevedo S.S., Pena H.F.J., Alves C.J., Guimarães-Filho A.A.M., Oliveira R.M., Maksimov P., Schares G. \& Gennari S.M. 2010. Prevalence de anti-Toxoplasma gondii e Neospora caninum antibodies in swine from Northeastern Brazil. Revta Bras. Parasitol. Vet. 19(2):80-84.

Dubey J.P. 2009. Toxoplasmosis in pigs: the last 20 years. Vet. Parasitol. 164(2/4):89-103.

Dubey J.P. 2010. Toxoplasmosis of Animals and Humans. $2^{\text {nd }}$ ed. CRC Press, Boca Raton, FL, p.1-313.

Dubey J.P. \& Jones J.L. 2008. Toxoplasma gondii infection in humans and animals in the United States. Int. J. Parasitol. 38:1257-1278.

Dubey J.P., Bhaiyat M.I., Allie C., MacPherson C.N.L., Sharma R.N., Sreekumar C., Vianna M.C.B., Shen S.K., Kwok O.C.H., Miska K.B., Hill D.E. \& Lehmann T. 2005. Isolation, tissue distribution, and molecular characterization of Toxoplasma gondii from chickens in Grenada. J. Parasitol. 91(3):557-560.

Dubey J.P., Sundar N., Gennari S.M., Minervino A.H.H., Farias N.A.R., Ruas J.L., Santos T.R.B., Cavalcante G.T., Kwok OC.H. \& Su C. 2007. Biologic and genetic comparison of Toxoplasma gondii isolates in free-range chickens from the northern Pará state and the southern state Rio Grande do Sul, Brazil revealed highly diverse and distinct parasite populations. Vet. Parasitol. 143(2):182-188.

Dubey J.P., Sundberg J.P. \& Matiuck S.W. 1981. Toxoplasmosis associated with abortion in goats and sheep in Connecticut. Am. J. Vet. Res. 42:1624-1626.

Dubey J.P. 1998. Refinement of pepsin digestion method for isolation of Toxoplasma gondii from infected tissues. Vet. Parasitol. 74:75-77.

Dubey J.P. \& Frenkel J.K. 1973. Experimental Toxoplasma infection in mice with strains producing oocyts. J. Parasitol. 59:505-512.

Dubremetz J.F. \& Lebrun M. 2012. Virulence factors of Toxoplasma gondii. Microbes Infect. 14:1403-1410.

Fernandes E.F.T.S., Fernandes M.F.T.S., Kim P.C.P., Albuquerque P.P.F., Neto O.L.S., Santos A.S., Moraes É.P.B.X., Morais E.G.F. \& Mota R.A. 2012. Study of Toxoplasma gondii in slaughtered swine in the state of Pernambuco, Brazil. J. Parasitol. 98(3):690-691.

Ferreira A.M., Vitor R.T.G. \& Melo M.N. 2006. Genetic analysis of natural recombinant Brazilian Toxoplasma gondii strains by multilocus PCR-RFLP. Infect. Genet. Evol. 6:22-31.

Ferreira A.M., Martins M.S. \& Vitor R.W.A. 2001.Virulence for Balb-c mice and antigenic diversity of eight Toxoplasma gondii strains isolated from animals and humans in Brazil. Parasite 8:99-105.

Frazão-Teixeira E., Oliveira F.C.R., Pelissari-Sant'Ana V. \& Lopes C.W.G. 2006. Toxoplasma gondii em encéfalos de suínos comercializados no município de Campos dos Goytacazes, Estado do Rio de Janeiro. Revta Bras. Parasitol. Vet. 15(1):33-36.

Freitas J.A., Oliveira J.P., Ramos O.S. \& Ishizuka M.M. 2009. Frequência de anticorpos anti-Toxoplasma gondii em suínos abatidos sem inspeção em Belém. Arq. Bras. Med. Vet. Zootec. 61(5):1230-1232.

Garcia J.L., Gennari S.M., Machado R.Z. \& Navarro I.T. 2006. Toxoplasma gondii: detection by mouse bioassay, histopathology, and polymerase chain reaction in tissues from experimentally infected pigs. Exp. Parasitol. 113(4):267-271.

Garcia J.L., Navarro I.T., Ogawa L. \& Oliveira R.C. 1999. Soroprevalência de Toxoplasma gondii em suínos, bovinos, ovinos e equinos, e sua correlação com humanos, felinos e caninos, oriundos de propriedades rurais do norte do Paraná, Brasil. Ciência Rural 29(1):91-97.

Howe D.K. \& Sibley L.D. 1995. Toxoplasma gondii comprises three clonal lineages: correlation of parasite genotype with human disease. J. Infect. Dis. 172:1561-1566.

Jacobs L. \& Melton M.L. 1954. Modification in virulence of a strain of Toxoplasma gondii by passage in various hosts. Am. J. Trop. Med. Hyg. 3:447457.

Jacobs L. \& Melton M.L. 1966.Toxoplasmosis in chickens. J. Parasitol. 52:1158-1162.

Jongert E., Melkebeek V., De Craeye S., Dewit J., Verhelst D. \& Cox E. 2008.
An enhanced GRA1-GRA7 cocktail DNA vaccine primes anti-Toxoplasma immune responses in pigs. Vaccine 26:1025-1031.

Johnson A.M. 1997. Speculation on possible life cycles for the clonal lineages in the genus Toxoplasma. Parasitology Today 13(10):393-397.

Kaufman H.E., Remington J.S. \& Jacobs L. 1958. Toxoplasmosis: the nature of virulence. Am. J. Ophthalmol. 46:255-261.

Kaufman H.E., Melton M.L., Remington J.S. \& Jacob L. 1959. Strains differences in Toxoplasma gondii. J. Parasitol. 45:189-90.

Khan A., Jordan C., Muccioli C., Vallochi A.L., Rizzo L.V., Belfort Jr R., Vitor R.W.A., Silveira C. \& Sibley L.D. 2006. Genetic divergence of Toxoplasma gondii strains associated with ocular toxoplasmosis, Brazil. Emerg. Infect. Dis. 12:942-949.

Kijlstra A., Meerburg B., Cornelissen J., De Craeye S., Vereijken P. \& Jongert E. 2008. The role of rodents and shrews in the transmission of Toxoplasma gondii to pigs. Vet. Parasitol. 156:183-190.

Kuticic V. \& Wikerhauser T. 2000. A survey of chickens for viable toxoplasms in Croatia. Acta Vet. Hung. 48:183-185.

Lehmann T., Marcet P.L., Graham D.H., Dahl E.R. \& Dubey J.P. 2006. Globalization and the population structure of Toxoplasma gondii. Proc. Natl Acad. Sci. USA 103:11423-11428.

Luciano D.M., Menezes R.C., Ferreira L.C., Nicolau J.L., Neves L.B., Luciano R.M., Dahroug M.A.A. \& Amendoeira M.R.R. 2011. Occurrence of anti-Toxoplasma gondii antibodies in cattle and pigs slaughtered, State of Rio de Janeiro. Revta Bras. Parasitol. Vet. 20(4):351-353.

Millar P.R., Daguer H., Vicente R.T., Costa T., Sobreiro L.G. \& Amendoeira M.R.R. 2008. Toxoplasma gondii: estudo soro-epidemiológico de suínos da região Sudoeste do Estado do Paraná. Pesq. Vet. Bras. 28(1):15-18.

Mitsuka R., Silva A.C.B., Navarro I.T., Breganó J.W. \& Vidotto O. 1998. Toxoplasma gondii: avaliação da virulência de oito amostras. Braz. J. Vet. Res. Anim. Sci. 1:29-31.

Muraro L.S., Caramori Júnior J.G., Amendoeira M.M.R., Pereira J.A., Oliveira Filho J.X., Vicente R.T., Neves L.B., Nicolau J.L., Igarashi M. \& Moura S.T. 2010. Seroprevalence of Toxoplasma gondii infection in swine matrices in Nova Mutum e Diamantino, Mato Grosso do Sul, Brazil. Revta Bras. Parasitol. Vet. 19(4):254-255.

Pena H.F.J., Gennari S.M., DubeyJ.P. \& Su C. 2008. Population structure and mouse-virulence of Toxoplasma gondii in Brazil. Int. J. Parasitol. 5:561569.

Pereira S.D. 2004. Conceitos e definições em epidemiologia importantes para vigilância sanitária. Centro de Vigilância Sanitária. Disponível em<http://www.cvs.saude.sp.gov.br> Acesso em 5 fev. 2014.

Piassa F.R., Araújo J.B., Rosa R.C., Mattei R.J., Silva R.C., Langoni H. \& Silva A.V. 2010. Prevalence and risk factors for Toxoplasma gondii infection in certified and non-certified pig breed in farms in the Toledo microregion, PR, Brazil. Revta Bras. Parasitol. Vet. 19(3):152-156.

Santos C.B., Carvalho A.C., Ragozo A.M., Soares R.M., Amaku M., Yai L.E., DubeyJ.P. \& Gennari S.M. 2005. First isolation and molecular characterization of Toxoplasma gondii from finishing pigs from São Paulo state, Brazil. Vet. Parasitol. 131:207-211.

Sreekumar C., Graham D.H., Dahl E., Lehmann T., Raman M., Bhalerao D.P., ViannaM.C. \& Dubey J.P. 2003. Genotyping of Toxoplasma gondii isolates from chickens from India. Vet. Parasitol. 118:187-194.

Su C., Zhang X. \& Dubey J.P. 2006. Genotyping of Toxoplasma gondii by multilocus PCR-RFLP markers: a high resolution and simple method for identification of parasites. Int. J. Parasitol. 36:841-848.

Tsunematsu Y., Shioiri K. \& Kusano N. 1964.Three cases of lymphadenopathia toxoplasmotica with special reference to the application of fluorescent antibody technique for detection of Toxoplasma in tissue. Jpn. J. Exp. Med. 34:217-230.

Velmurugan G.V., Su C. \& Dubey J.P. 2009. Isolate designation and characterization of Toxoplasma gondii isolates from pigs in the United States. J. Parasitol. 1:95-99.

Willians D.M., Grumet F.C. \& Remington J.S. 1978.Genetic control of murine resistance to Toxoplasma gondii. Infect. Immun. 19:416-420. 